\title{
Impacts of MJO on the Intraseasonal Temperature Variation in East Asia
}

\author{
SUNYONG KIM AND JONG-SEONG KUG \\ Division of Environmental Science and Engineering, Pohang University of Science and Technology, Pohang, Gyeongbuk, \\ South Korea \\ KYONG-HwAN SEO \\ Department of Atmospheric Sciences, Pusan National University, Busan, South Korea
}

(Manuscript received 26 April 2020, in final form 20 July 2020)

\begin{abstract}
The Madden-Julian oscillation (MJO) is closely related to the intraseasonal variability of surface temperature in East Asia. It has been shown that significant cold surface temperature anomalies are observed in East Asia during MJO phase 3. However, the cooling tendency develops prior to phase 3, suggesting that the cold surface anomalies in East Asia are a delayed and accumulated response to the MJO forcings prior to phase 3 . Here, using a thermodynamic equation, it is shown that both meridional advection and adiabatic cooling terms associated with the MJO flow are the dominant contributors to the cooling tendency. The meridional cold advection initially manifests in East Asia in the form of northerly wind anomalies in the eastern part of anticyclonic circulation anomalies that are centered over eastern Europe and develop before the establishment of the cold anomalies. It is suggested that the enhanced convection in the western North Pacific Ocean is responsible for the anomalous anticyclonic flow over eastern Europe with about a 10-day lag via a meridionally propagating Rossby wave train. Further, cooling by the vertical wind component in East Asia is a result of adiabatic cooling interpreted as a reversed local overturning circulation, with downward motion in the tropics and upward motion in the subtropics. This anomalous meridional overturning circulation process initiated from suppressed convection spanning the tropical Indian Ocean to East Asia also takes about 10 days. Therefore, both the Rossby wave propagation and a local overturning circulation induced by the tropical convections play an important role in driving the lagged response of cold surface anomalies in East Asia. Interestingly, these tropical convection forcings are similar to the typical dipole pattern in convection during MJO phase 7, with suppressed Indian Ocean convection and enhanced western North Pacific convection. This implies that the dipole convective forcing during MJO phase 7 possibly leads to the cold anomalies in East Asia following phase 3 .
\end{abstract}

KEYWORDS: Madden-Julian oscillation; Cold air surges; Teleconnections

\section{Introduction}

The Madden-Julian oscillation (MJO) is the dominant mode of intraseasonal variability in the tropics, represented as an eastward-propagating circulation from the Indian to the Pacific Oceans along the equatorial region with a time scale of 30-60 days (Madden and Julian 1971, 1972). Great progress in understanding the mechanisms for MJO propagation has been made including the skeleton theory (Majda and Stechmann 2009), the gravity wave theory (Yang and Ingersoll 2013), the trio-interaction theory (Wang et al. 2016), and coupled Rossby-Kelvin wave dynamics (Wang and Rui 1990) with moisture mode theory (Sobel and Maloney 2013; Wang et al. 2017; Wang and Li 2020). Previous studies have suggested that the tropical diabatic heating associated with the MJO influences the weather and climate not only in the tropics but also the extratropics via equatorially trapped Kelvin and Rossby waves and an extratropical Rossby wave train, respectively (Matthews et al. 2004; Seo and Son 2012; Wang et al. 2013; Adames and Wallace 2014; Stan et al. 2017). In particular, extratropical responses to the MJO forcing have been shown to modulate precipitation in the United States (Mo and Higgins 1998; Jones 2000; Bond and Vecchi 2003), South America

Corresponding author: Jong-Seong Kug, jskug1@gmail.com
(Paegle et al. 2000), southwest Asia (Barlow et al. 2005), and East Asia (Jeong et al. 2008; He et al. 2011) and global occurrences of extreme precipitation events (Jones et al. 2004), temperature in the northern high latitudes (Vecchi and Bond 2004) and midlatitude continental regions (Seo et al. 2016), and cold surge occurrences in East Asia (Jeong et al. 2005).

In the midlatitudes, where anomalous circulation induced by the MJO evolution results, it is well known that the intraseasonal variability in East Asian climate is especially affected by dominant MJO signals. Indeed, when MJO-related enhanced convection is located in the tropical Indian Ocean or western Pacific, a chain of cyclonic and anticyclonic disturbances typically develops downstream over regions of the upper-level convective outflow as a result of the Rossby wave response (Rui and Wang 1990), and situated mainly in the exit region of the East Asian jet (Knutson and Weickmann 1987; Hsu 1996).

According to Jeong et al. (2005), the spatial pattern and magnitude of surface air temperature anomalies in East Asia significantly change with respect to the MJO phases. Extreme cold anomalies predominantly occur when the MJO convection is located in the tropical Indian Ocean (i.e., MJO phase 3), suggesting strong phase dependency of the MJO cycle. The MJO-related anomalously cold temperatures in East Asia are partly explained by the strong cold advection in the lower- 
tropospheric trough near Siberia result of both the advective and radiative processes. The cold surface anomalies occur under dry air due to the positive relationship between the midtropospheric specific humidity and downward longwave radiation (Adams et al. 2000). However, it was suggested that most cold anomalies are triggered more by midlatitude variations themselves, and that the MJO-induced circulation anomalies may only be regarded as supplementary synoptic conditions (Jeong et al. 2005).

More recently, Seo et al. (2016) detailed the dynamical processes of how MJO affects the East Asian climate. From a thermodynamic budget analysis, the vertical advection of the basic-state temperature field by MJO-induced vertical velocity largely accounts for the temperature tendency in East Asia. The warming tendency in East Asia following MJO phase 3 is associated with the significant adiabatic subsidence forced by the MJO-related tropical convection. A local meridional overturning circulation induced by the tropical upward motion forced by convective heating generates the subtropical downward motion leading to adiabatic subsidence after MJO phase 3 at $10-15$ days lag.

It is well known that the direct, quasi-steady extratropical response to the tropical heating can be established in about 2 weeks, as detailed in Jin and Hoskins (1995). Seo et al. (2016) also showed that such a lagged relationship occurs between the MJO and Northern Hemisphere teleconnections, especially in East Asia, North America, and eastern Europe. According to Lin et al. (2009), about 10-15 days after MJO phase 3 a positive phase of the North Atlantic Oscillation (NAO) tends to develop, which has long been recognized as a dominant circulation pattern that can influence the weather over the regions from North America to Europe (Hurrell 1995). The circulation responses to $\mathrm{MJO}$ forcing develop over time as the Rossby waves propagate meridionally, such that the circulation anomalies induced by the MJO in the midlatitude exhibit a lagged response (Matthews et al. 2004; Cassou 2008; Yoo et al. 2012). Therefore, lagged impacts of the MJO signal are likely to exist for the East Asian climate.

In this study, we extend these studies by focusing more closely on the winter climate in East Asia by considering any lagged and/or accumulated response to the tropical MJO forcing. The surface cold anomalies in East Asia during MJO phase 3 have in fact demonstrated (Jeong et al. 2005; Seo et al. 2016); however, the detailed dynamical mechanisms and their lagged responses to the tropical MJO convection have not been understood. Therefore, possible dynamical processes inducing the East Asian surface temperature variations in response to the MJO forcing are proposed using an intraseasonal perturbation thermodynamic equation. The question that can be also addressed here is whether leading tropical convective forcing responsible for the East Asian surface cooling during phase 3 resembles the typical convection pattern of MJO. If so, which MJO phase? We explicitly show the lead-lag relationship between MJO-related tropical convective activity and temperature variation in East Asia on the intraseasonal time scale.

\section{Data and methods}

The data used in this study included the National Centers for Environmental Prediction-National Center for Atmospheric
Research (Kalnay et al. 1996) daily mean air temperature, geopotential height, horizontal wind, and pressure velocity. Advanced Very High Resolution Radiometer daily mean outgoing longwave radiation (OLR) data from the National Oceanic and Atmospheric Administration (Liebmann and Smith 1996) were also utilized. Both datasets are on a $2.5^{\circ}$ latitude-longitude grid. To extract intraseasonal variability, the anomaly field for each variable was derived by removing the time mean and first three harmonics of annual cycle and passed through a bandpass filter (20-90 day) on the resulting anomalies using a Lanczos filter. Only the winter season [December-February (DJF)] was considered for the period from 1979 to 2017.

Following Matthews (2000), the MJO cycle was defined by an empirical orthogonal function (EOF) analysis of filtered OLR in the tropics $\left(30^{\circ} \mathrm{S}-30^{\circ} \mathrm{N}\right)$. The two leading EOF modes were used to define the MJO, and the combination of the two associated principal component (PC) series to represent the typical eastward-propagating MJO signal. Using the two leading EOF modes and PCs, the MJO cycle was constructed with eight different phases, that is, enhanced convection in the tropical Indian Ocean during phases 2 and 3, in the Maritime Continent during phases 4 and 5, in the western Pacific during phases 6 and 7, and in the Western Hemisphere and Africa during phases 8 and 1 (Wheeler and Hendon 2004). The distance of a point from the origin $\left(\mathrm{PC}^{2}+\mathrm{PC}^{2}\right)^{1 / 2}$ can be considered as the MJO amplitude, and an active MJO event defined as a period of time when the MJO amplitude is greater than 1.5 for each phase.

To derive the intraseasonal temperature diagnostics, the perturbed thermodynamic equation used here is as follows (Seo et al. 2016):

$$
\begin{aligned}
\frac{\partial\{T\}}{\partial t}= & -\overline{\mathbf{V}_{H}} \cdot \nabla_{H}\{T\}-\left\{\mathbf{V}_{H}\right\} \cdot \nabla_{H} \bar{T}-\left\{\mathbf{V}_{H}^{\prime} \cdot \nabla_{H} T^{\prime}\right\} \\
& +\left(\frac{R}{C_{p}} \frac{\{T\}}{P}-\frac{\partial\{T\}}{\partial p}\right) \bar{\omega}+\left(\frac{R}{C_{p}} \frac{\bar{T}}{P}-\frac{\partial \bar{T}}{\partial p}\right)\{\omega\} \\
& +\left(\left\{\frac{R}{C_{p}} \frac{T^{\prime}}{P} \omega^{\prime}\right\}-\left\{\frac{d T^{\prime}}{d p} \omega^{\prime}\right\}\right)+\left\{Q_{\text {Dia }}\right\}+\{\text { Res }\}
\end{aligned}
$$

where the overbar denotes the DJF mean, the prime indicates the total anomaly, and the curly braces represent the intraseasonal component; $T$ is the temperature, $\mathbf{V}_{H}$ is the horizontal wind, and $\omega$ is the vertical velocity in the pressure coordinates; $R$ is the gas constant for dry air, $C_{p}$ is the specific heat of dry air at constant pressure, $p$ is the pressure, and $Q_{\text {Dia }}$ is the diabatic heating estimated from the apparent heat source (Yanai et al. 1973). Res is a residual term containing diffusion effects and numerical error.

In Eq. (1), the left-hand term is the intraseasonal temperature anomaly tendency. The first three terms on the right-hand side are the horizontal temperature advections of the intraseasonal temperature anomaly by the mean horizontal wind and of the mean temperature by intraseasonal horizontal wind anomaly, and the nonlinear advection between two anomalies, respectively. The subsequent three terms are the adiabatic 
heating, which corresponds to the interactions between the intraseasonal temperature anomaly and the mean vertical velocity and between the mean temperature and the intraseasonal vertical velocity anomaly, and the nonlinear advection between two anomalies, respectively. The seventh term represents the intraseasonal component of the diabatic heating and the residual term is considered negligible.

To reveal the tropics-extratropics teleconnection as evidence of Rossby wave propagation, the Rossby wave activity flux $\mathbf{W}$ was calculated. The wave activity flux formula used here is a phase-independent wave activity flux developed by Takaya and Nakamura (2001). A two-dimensional wave activity flux is expressed as follows:

$$
\mathbf{W}=\frac{1}{2|\overline{\mathbf{U}}|}\left[\begin{array}{l}
\bar{u}\left(\psi_{x}^{\prime 2}-\psi^{\prime} \psi_{x x}^{\prime}\right)+\bar{v}\left(\psi_{x}^{\prime} \psi_{y}^{\prime}-\psi^{\prime} \psi_{x y}^{\prime}\right) \\
\bar{u}\left(\psi_{x}^{\prime} \psi_{y}^{\prime}-\psi^{\prime} \psi_{x y}^{\prime}\right)+\bar{v}\left(\psi_{y}^{\prime 2}-\psi^{\prime} \psi_{y y}^{\prime}\right)
\end{array}\right],
$$

where the $\psi$ denotes the streamfunction, $\overline{\mathbf{U}}$ is the zonal and meridional components of basic flows, and the subscript indicates the partial derivative.

\section{Results}

\section{a. MJO teleconnection in East Asia}

The surface air temperature fields in East Asia vary considerably depending on the canonical eight phases of the MJO, exhibiting strong phase dependency (Fig. 1). The most distinct feature is the overall opposite temperature patterns for phases 1-4 and phases 5-8, elucidating the somewhat antisymmetric responses of the two half cycles. In particular, during phase 3, defined as the enhanced convection in the central Indian Ocean and the suppressed convection in the tropical western Pacific, significant cold anomalies dominate East Asia (Fig. 1c), and the opposite pattern appears during phase 7 (Fig. 1g). In addition, most extreme cold surges in East Asia tend to occur during phase 3 (Jeong et al. 2005), suggesting that the MJOinduced circulation anomalies may reinforce cold surges in this region. Therefore, in this study the dynamical processes through which the MJO affects the cold anomalies in East Asia are further examined.

Figure 2 shows the lead-lag composites of surface temperature anomalies and its tendency from lag day -8 to day +10 during phase 3 at 2-day intervals. On day -8 , cold anomalies appear in eastern Europe (Fig. 2a), implying that they may initiate during phases 1 and 2 when the MJO convection anomalies are located over Africa and the central Indian Ocean. Subsequently, the cold anomalies strengthen and extend across East Asia until day 0 (Figs. 2b-e). The magnitude of the cold anomalies in the East Asian region $\left(60^{\circ}-120^{\circ} \mathrm{E}, 25^{\circ}-\right.$ $55^{\circ} \mathrm{N}$ ) is clearly maximized at day 0 during phase 3 (Fig. 2e). After day 0 , the cold anomalies weaken compared to that of day 0 , and warm anomalies start to develop in eastern Europe (Figs. 2f-j). This gradual weakening of cold anomalies in East Asia following phase 3 is consistent with that of Seo et al. (2016) suggesting the existence of a warm temperature tendency.

The temporal evolution of anomalous lower-level (i.e., $850 \mathrm{hPa}$ ) temperature tendency in East Asia centered on phase
3 is also shown in Fig. 2. A cooling tendency dominates East Asia on day -8 (Fig. 2a); however, it tends to weaken and move eastward afterward, leading to maximum cold anomalies in the East Asian region at day 0 (Fig. 2e). Concurrently with the decaying cooling tendency, the warming tendency develops, spreading from eastern Europe gradually to cover most of East Asia after phase 3 (Figs. 2f-j). As a result, the cold anomalies become weaker and alternatively the warm anomalies begin to appear at the surface between days 15 and 20 after the initial MJO phase 3 (not shown), as suggested in Seo et al. (2016).

Considering that the time interval for two consecutive MJO phases is about 5-7 days, the cold anomalies in East Asia seem to develop prior to MJO phase 3. This indicates that the surface temperature anomalies in East Asia during phase 3 are not a direct response to anomalous tropical convection associated with MJO phase 3, but a lagged response to preceding convective forcings associated with prior MJO phases. To quantify contributions of the individual terms in Eq. (1) to the cold surface anomalies in the East Asian region $\left(60^{\circ}-120^{\circ} \mathrm{E}, 25^{\circ}-\right.$ $55^{\circ} \mathrm{N}$ ) before and after phase 3, the area-averaged lead-lag composites of the major advection terms are shown in Fig. 3a. Note that each individual advection term is decomposed after masking out the majority of the Tibetan Plateau $\left(70^{\circ}-105^{\circ} \mathrm{E}\right.$, $25^{\circ}-45^{\circ} \mathrm{N}$ ) in the East Asian region.

Figure $3 \mathrm{a}$ shows that the steady cooling tendency before phase 3 responsible for the cold anomalies in East Asia is contributed to predominantly by two terms, namely, the meridional advection of time-mean temperature by the MJO meridional flow [i.e., $-\{v\}(\partial \bar{T} / \partial y)$ ] and the vertical advection of time-mean temperature by the MJO vertical flow (i.e., $\left.\left[\left(R / C_{p}\right)(\bar{T} / P)-(\partial \bar{T} / \partial p)\right]\{\omega\}\right)$. The meridional advection is the strongest component for the cooling tendency before phase 3 (Fig. 3a); however, it counteracts the warming tendency that develops after day 0 . This result suggests that the cooling in East Asia is mostly due to the meridional cold advection from the MJO-induced northerly wind anomalies. The vertical advection term, represented by anomalous upward motion, also shows a cooling tendency before day 0 of phase 3 and therefore also contributes to the cold anomalies in East Asia. The vertical advection term is a factor in the cooling tendency up to day -6 , before reversing sign and contributing to the warming. The time evolution of the vertical adiabatic term and its contribution to the warming tendency in East Asia after phase 3 are somewhat consistent with Seo et al. (2016). For example, they suggested that the East Asian warming is associated with the significant adiabatic subsidence in East Asia forced by the MJO-related tropical convection. This direct circulation can be interpreted as a local overturning circulation that consists of tropical upward motion forced by the active convection and downward motion leading to the adiabatic warming in the subtropics. However, Seo et al. (2016) focused only on the vertical advection in terms of the total temperature tendency in East Asia; therefore, the detailed dynamics of the meridional advection caused by $\mathrm{MJO}$ forcing will be discussed in section $3 b$.

The evolution of cold anomalies in East Asia centered on phase 3 as shown in Fig. 2 indicates a distinct southeastward- 

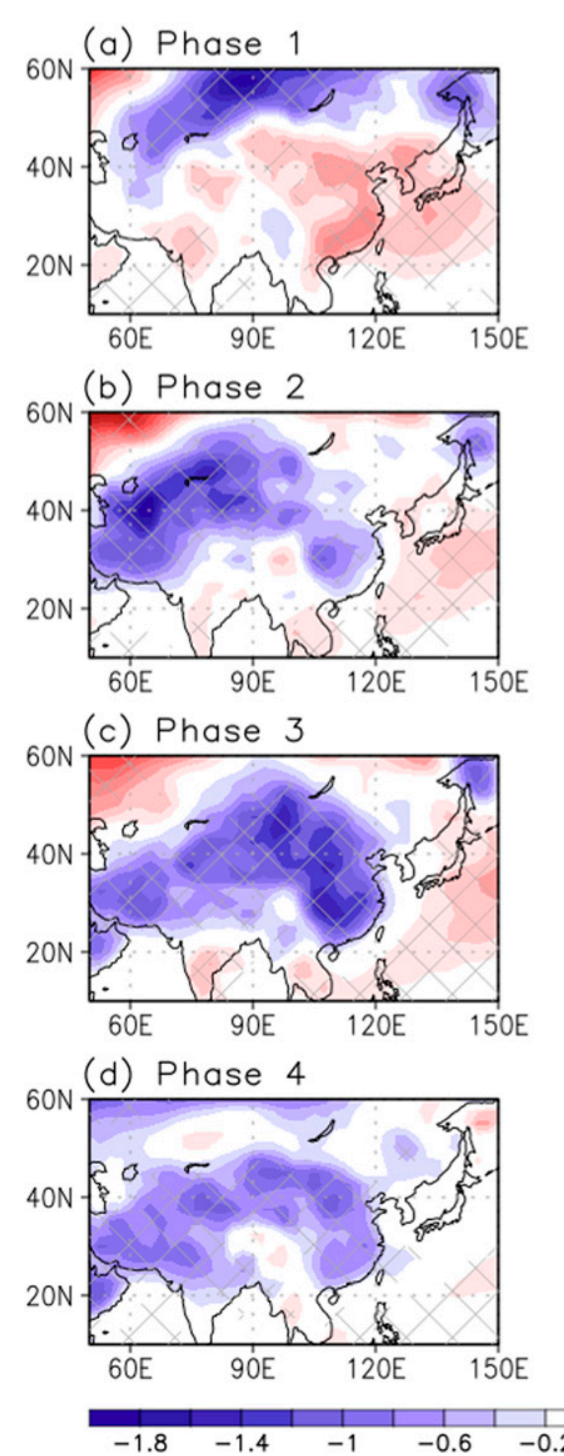

FIG. 1. Composites of air temperature (shading; K) anomalies at $2 \mathrm{~m}$ for the eight phases of the MJO during the winter season (DJF) from 1979 to 2017. Cross hatches denote statistically significant regions at the $95 \%$ confidence level as based on Student's $t$ test. propagating feature, with primarily zonal (meridional) propagation in the first (second) half of the period. For example, the maximum cold center moves from the northern to the eastern part of East Asia. Yang and Li (2016) showed that the intraseasonal temperature perturbation in boreal winter propagates southeastward in the mid-high latitudes of Eurasia and gains energy from the mean flow through both kinetic and potential energy conversion. The cause of this southeastward aligned pathway of surface temperatures in East Asia may be related to the topographic effect of the Tibetan Plateau (Yang and Li 2017; Zhao et al. 2017). The Tibetan Plateau is the largest and highest plateau in the world with an average elevation exceeding $4500 \mathrm{~m}$ (Qiu 2008); therefore, there should be a local intraseasonal variation around the Tibetan Plateau. Here, the temperature budgets for subregions of East Asia are calculated,
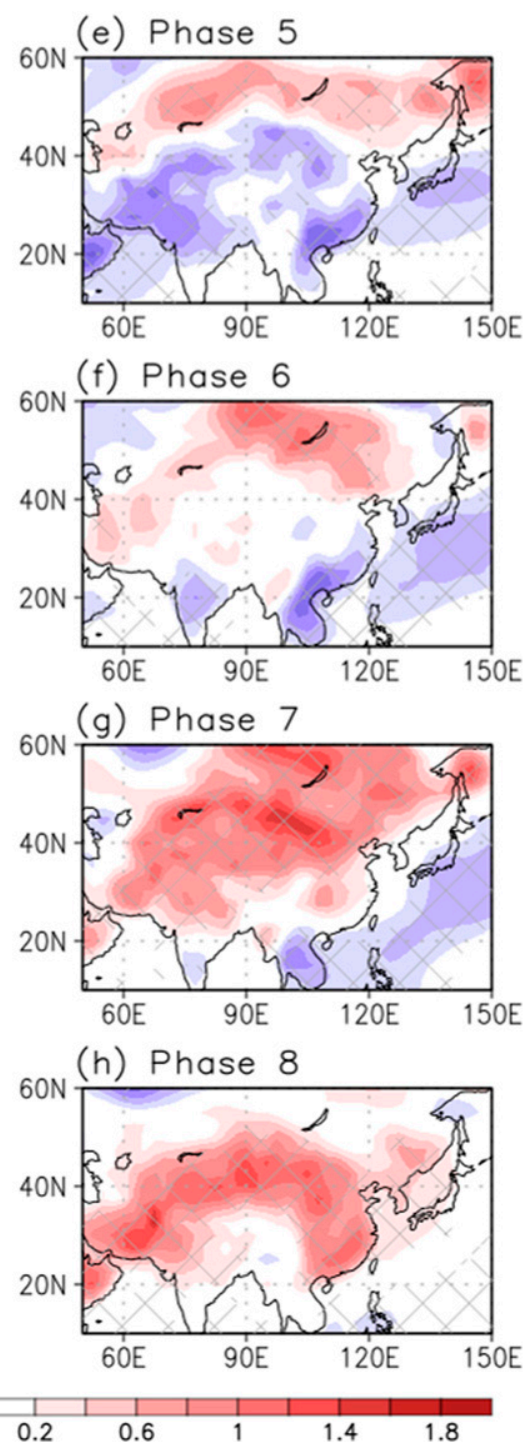

with the northern $\left(60^{\circ}-90^{\circ} \mathrm{E}, 45^{\circ}-55^{\circ} \mathrm{N}\right)$ and the eastern part $\left(105^{\circ}-120^{\circ} \mathrm{E}, 25^{\circ}-45^{\circ} \mathrm{N}\right)$ following the southeastward pathway and removing the Tibetan Plateau effect.

In northern East Asia, the maximum cold anomalies appear at day -3 (Fig. 3b), preceding the overall East Asian cold anomalies. The meridional and vertical advections are still the dominant contributors to the total cooling tendency. In addition, the zonal advection of MJO-related temperature by the time-mean zonal flow $[-\bar{u}(\partial\{T\} / \partial x)]$ plays a partial role in promoting the cooling tendency before day -6 and then reverses to contribute to the warm advection.

The maximum cold anomalies in eastern East Asia exist at day 3 , implying the clear southeastward migration of intraseasonal temperature anomalies from the northern to eastern regions of East Asia (Fig. 3c), consistent with Fig. 2. The 


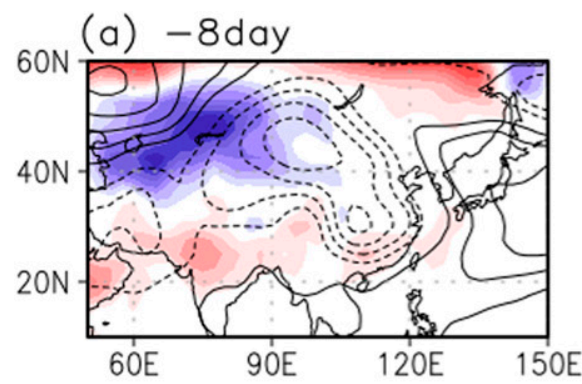

(b) -6 day

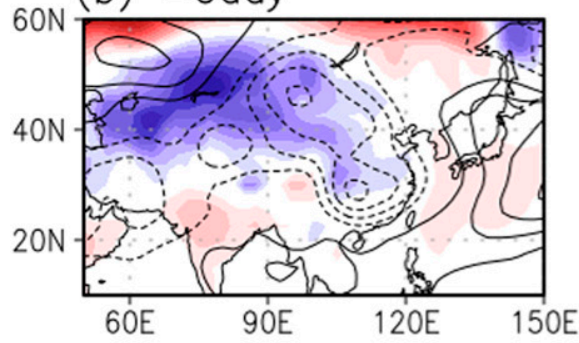

(c) -4 day

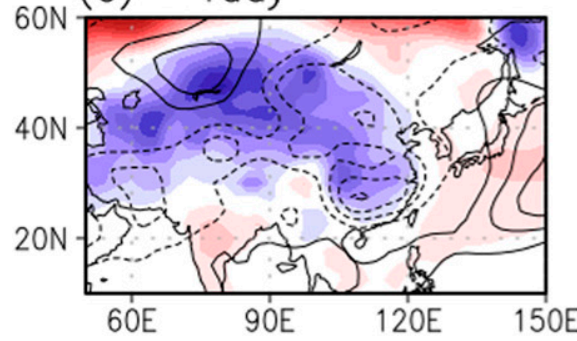

(d) -2 day

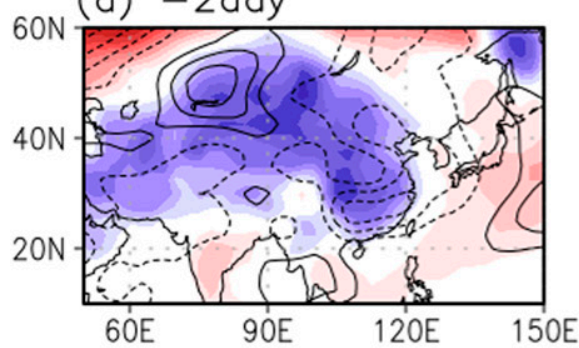

(e) Oday

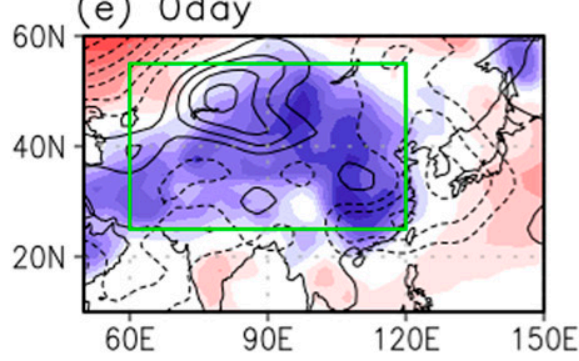

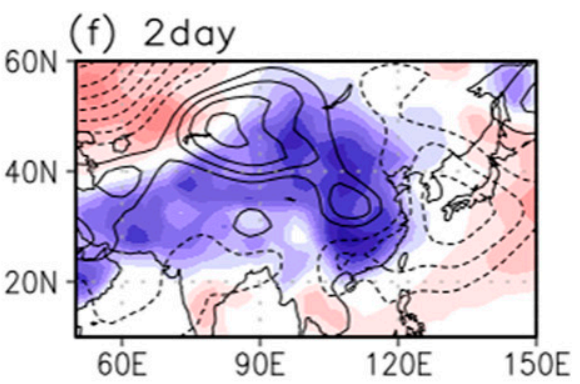
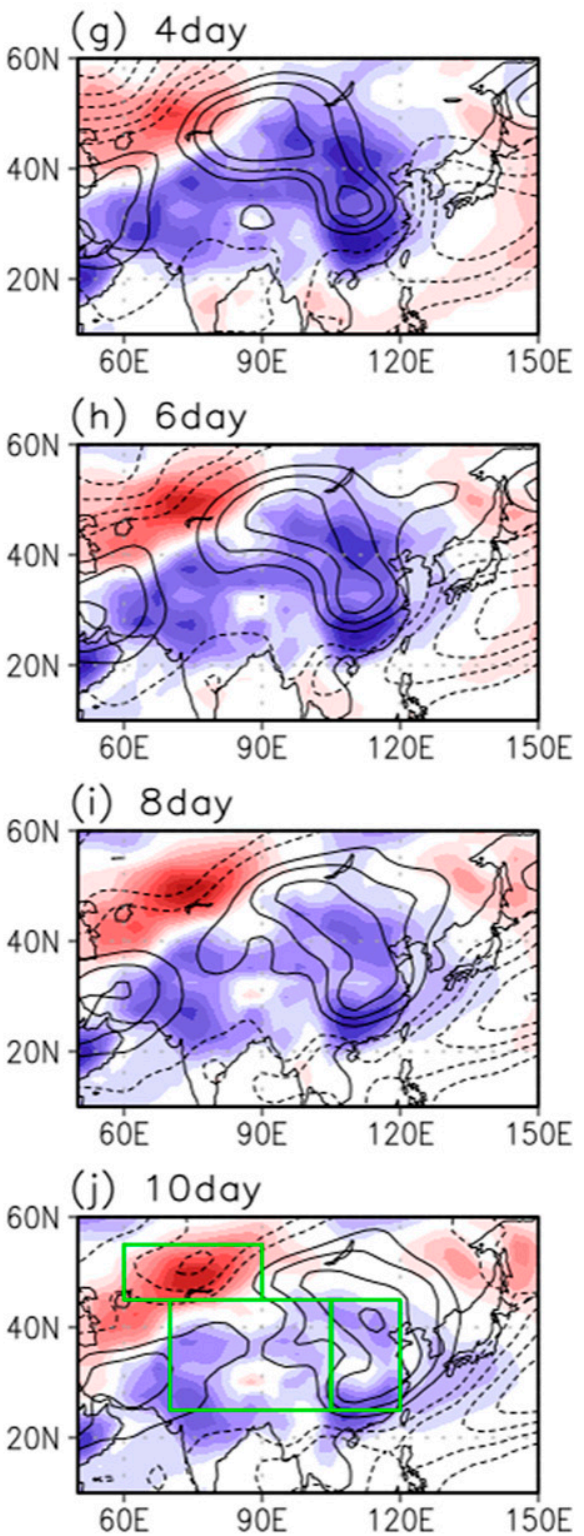

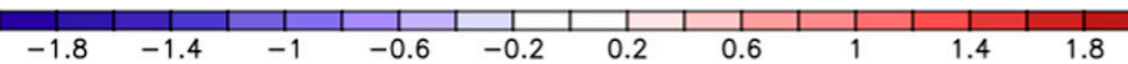

FIG. 2. Composites of the evolutions in air temperature (shading; K) anomalies at $2 \mathrm{~m}$ and temperature tendency (contours; $\mathrm{K} \mathrm{day}^{-1}$ ) at $850 \mathrm{hPa}$ in East Asia from day -8 to day 10 , with an interval of 2 days, for the initial MJO phase 3. The temperature tendency term is decomposed after masking out the topographic effect of the Tibetan Plateau [shown by the bottom-left green-outlined rectangle in (j): $70^{\circ}-105^{\circ} \mathrm{E}, 25^{\circ}-45^{\circ} \mathrm{N}$ ]. The East Asian [in (e); $60^{\circ}-120^{\circ} \mathrm{E}, 25^{\circ}-55^{\circ} \mathrm{N}$ ], northern East Asian [in (j) at top; $60^{\circ}-90^{\circ} \mathrm{E}, 45^{\circ}-55^{\circ} \mathrm{N}$ ], and eastern East Asian [in (j) at bottom right; $105^{\circ}-120^{\circ} \mathrm{E}, 25^{\circ}-45^{\circ} \mathrm{N}$ ] regions are also indicated by green-outlined rectangles. 

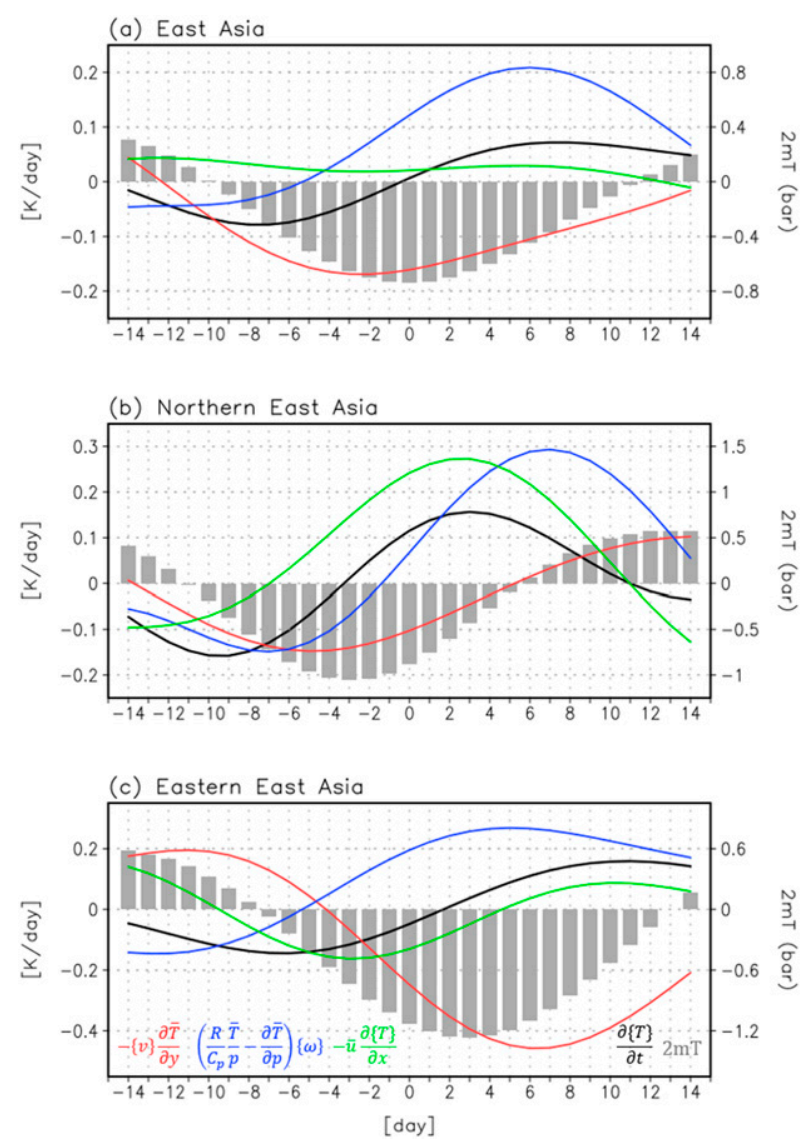

FIG. 3. Time evolution in area-averaged air temperature (gray bars; K) anomalies at $2 \mathrm{~m}$, temperature tendency (black lines; $\mathrm{K} \mathrm{day}^{-1}$ ), meridional advection of time-mean temperature by the MJO meridional flow (red lines; $\mathrm{K} \mathrm{day}^{-1}$ ), vertical advection of time-mean temperature by the MJO vertical flow (blue lines; $\mathrm{K}_{\text {day }}{ }^{-1}$ ), and zonal advection of MJO temperature by time-mean zonal flow (green lines; $\mathrm{K} \mathrm{day}^{-1}$ ) at $850 \mathrm{hPa}$ for the initial MJO phase 3 in (a) East Asia (Fig. $2 \mathrm{e} ; 60^{\circ}-120^{\circ} \mathrm{E}, 25^{\circ}-55^{\circ} \mathrm{N}$ ), (b) northern East Asia (Fig. 2 j; $60^{\circ}-90^{\circ} \mathrm{E}, 45^{\circ}-55^{\circ} \mathrm{N}$ ), and (c) eastern East Asia (Fig. $2 \mathrm{j} ; 105^{\circ}-120^{\circ} \mathrm{E}, 25^{\circ}-45^{\circ} \mathrm{N}$ ). The temperature tendency and advection terms are decomposed after masking out the topographic effect of the Tibetan Plateau $\left(70^{\circ}-105^{\circ} \mathrm{E}, 25^{\circ}-45^{\circ} \mathrm{N}\right)$.

meridional advection contributes to the cooling tendency from day -4 ; however, it is mostly out of phase with the temperature tendency for the remainder of the time. This strong meridional cold advection tends to be offset by the vertical term and diabatic heating term ( $\left\{Q_{\text {Dia }}\right\}$; not shown), with a warming tendency after day 1 of phase 3 . Adiabatic cooling occurs prior to day -6 , before the vertical term leads to the warming tendency by adiabatic warming. Interestingly, the major contribution to the cooling tendency in eastern East Asia is that of zonal advection. The eastward cold advection of the temperature perturbation by the mean westerlies [i.e., $-\bar{u}(\partial\{T\} / \partial x)$ ] accounts for the cooling tendency, implying that the mean westerly winds play an important role for inducing the temperature tendency of eastern East Asia. That is, after generating the cold anomalies in the northwestern part of East Asia, the cold anomalies are advected toward eastern East Asia via the strong mean westerlies.

As shown in Fig. 3, both the meridional and vertical temperature advection by the intraseasonal flow contribute significantly to the cooling tendency in East Asia leading up to phase 3. A key question remains as to how the MJO-related convection induces the anomalous northerly wind and upward motion over East Asia. This is analyzed in the following sections.

\section{b. Meridional advection by $M J O$}

Figure 4 shows the evolution of lower-level circulation centered on phase 3 . Interestingly, the strong anticyclonic circulation anomalies exist near eastern Europe centered over $52.5^{\circ} \mathrm{N}, 57^{\circ} \mathrm{E}$ at day -6 (Fig. 4a). This anomalous anticyclonic flow persists but slowly weakens and is diminished by day 0 (Figs. 4b-e). Note that the lower-level anticyclonic signal somewhat resembles the upper-tropospheric height anomalies (not shown), suggesting a barotropic structure. On the eastern side of the anticyclonic circulation anomaly, significant northerly wind anomalies lead to the meridional cold advection toward East Asia.

Conversely, the atmospheric circulation patterns at $850 \mathrm{hPa}$ from day 2 to day 8 show the development of cyclonic circulation anomalies near eastern Europe (Figs. 4e-h). This anomalous cyclonic flow progressively intensifies, and it accompanies the southerly wind anomalies in the eastern part of the circulation. The southerly wind anomalies lead to the warm advection in northern East Asia, a role opposite to that with the anticyclonic circulation before day 0 . Therefore, the warm advection due to the southerly wind anomalies is partly responsible for the warming tendency in northern East Asia after day 6 of MJO phase 3 (Fig. 3b). Furthermore, in the eastern region of East Asia, the northerly wind anomalies persist during phase 3, contributing consistently to cold advection (Fig. 3c).

The distinct anticyclonic circulation anomalies centered over eastern Europe are noted in previous studies to display their strongest magnitude during phase 2 (Seo and Son 2012; Seo and Lee 2017), despite not being the main focus of their studies. Note that the anticyclone anomalies over eastern Europe that lead to the cold advection from northerly wind anomalies in East Asia develop before phase 3. That is, the cold anomalies in East Asia during phase 3 may be a result of a delayed and accumulated response to the MJO phases prior to phase 3. Therefore, there is a need to elucidate the detailed dynamical process involved in such lagged atmospheric circulation responses, such as anomalous anticyclonic flow in eastern Europe, to the tropical MJO forcing.

To identify the key mechanisms responsible for the development of anticyclonic circulation anomalies on the intraseasonal time scale, an area-averaged anticyclone index in eastern Europe $\left(40^{\circ}-60^{\circ} \mathrm{E}, 50^{\circ}-60^{\circ} \mathrm{N}\right)$ is calculated using the intraseasonally filtered geopotential height anomalies at $300 \mathrm{hPa}$ during DJF. To examine the relationship with the tropical convection, the leading OLR pattern is also calculated when the anticyclone index exceeds a one standard deviation threshold (Fig. 5a). It is found that the strong tropical OLR 

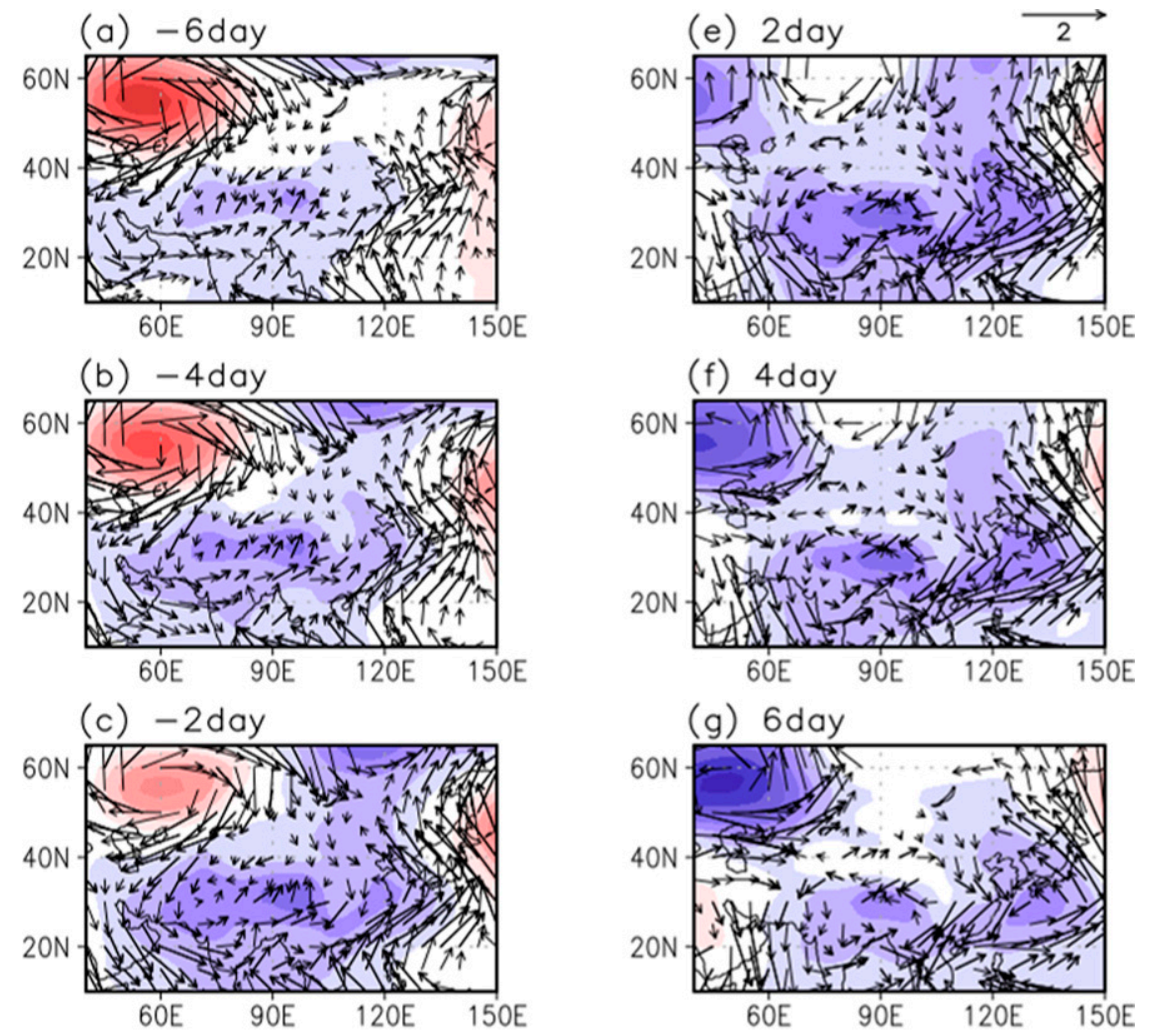

(e) Oday

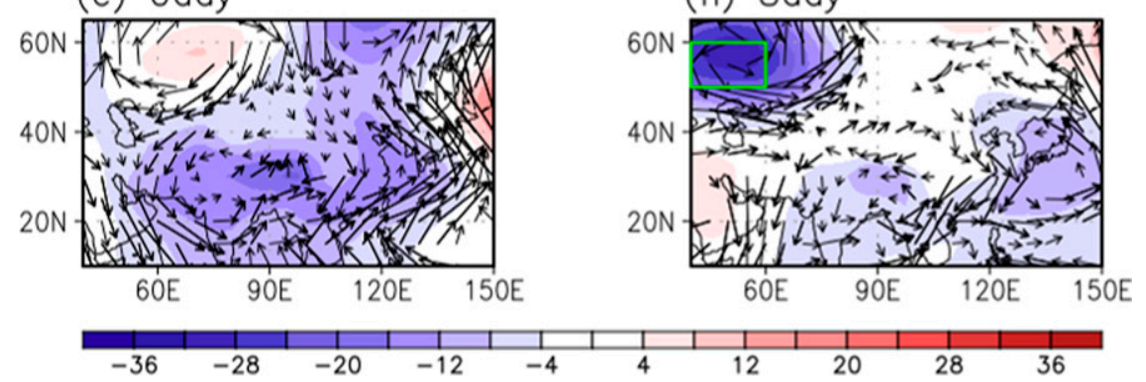

FIG. 4. Composites of the evolutions in geopotential height (shading; $\mathrm{m}$ ) and wind (vectors; $\mathrm{m} \mathrm{s}^{-1}$ ) anomalies at $850 \mathrm{hPa}$ in East Asia from day -6 to day 8 , with an interval of 2 days, for the initial MJO phase 3. Vectors represent statistically significant regions at the $95 \%$ confidence level as based on Student's $t$ test. The anomalous circulation over the eastern Europe $\left(40^{\circ}-\right.$ $60^{\circ} \mathrm{E}, 50^{\circ}-60^{\circ} \mathrm{N}$ ) region is indicated by the green-outlined rectangle in (h).

signals are most evident in 10-day lead composites, when they are observed in the tropical Indian Ocean and the western North Pacific (WNP), as shown in Fig. 5a. That is, 10 days after these dipole-like OLR patterns occurs, the anomalous anticyclonic flow appears over eastern Europe. According to Seo et al. (2016), for the waves coming from the Indian Ocean, only zonal wavenumbers 2 and 3 reach the extratropics; however, they dissipate near North America as a result of Rossby wave ray tracing. Yet, for cases emanating from the western Pacific, more waves including zonal wavenumber 4 propagate to downstream regions and passing through Europe, a process that also takes about $10-15$ days. Thus, the Rossby wave that is initiated by the convective activities in the western Pacific presumably affects the anticyclonic circulation anomalies located in eastern Europe. This result is also confirmed in Fig. 5b where the enhanced convection anomalies in the WNP $\left(120^{\circ}-140^{\circ} \mathrm{E}\right.$, $10^{\circ}-25^{\circ} \mathrm{N}$ ) have a maximum magnitude 10 days prior to the development of the anticyclonic flow in the eastern Europe region. Therefore, the cold anomalies in East Asia, formed partly as the result of the meridional cold advection may be the lagged response (of at least 10 days) forced by the MJO convection in the WNP.

The anomalous OLR patterns presented above are consistent with the typical MJO-related tropical convection during phases 6 or 7, although the enhanced convection anomalies are somewhat confined more to the WNP. The pattern correlation 

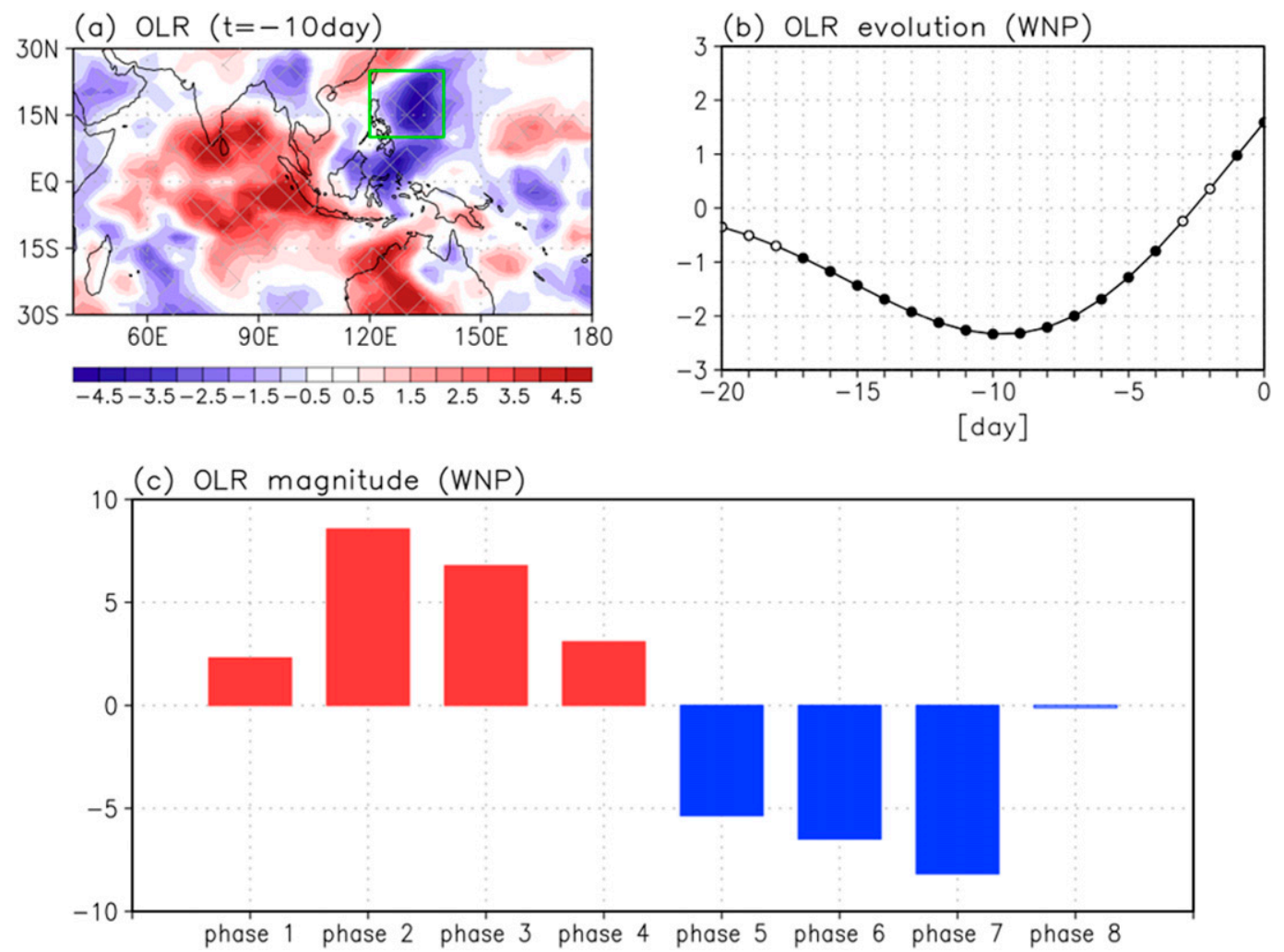

FIG. 5. (a) The leading OLR (shading; $\mathrm{W} \mathrm{m}^{-2}$ ) anomalies in the tropics 10 days before the area-averaged anticyclonic circulation anomalies at $300 \mathrm{hPa}$ in eastern Europe (Fig. $4 \mathrm{~h} ; 40^{\circ}-60^{\circ} \mathrm{E}, 50^{\circ}-60^{\circ} \mathrm{N}$ ) are greater than 1 standard deviation. (b) The leading evolution of area-averaged OLR anomalies in the WNP [green-framed rectangle in (a): $120^{\circ}-140^{\circ} \mathrm{E}, 10^{\circ}-25^{\circ} \mathrm{N}$ ] prior to the development of anticyclonic circulation anomalies in eastern Europe. (c) Composites of area-averaged OLR anomalies in the WNP for the eight phases of the MJO. Cross hatches in (a), closed circles in (b), and bars in (c) denote statistically significant areas at the $95 \%$ confidence level as based on Student's $t$ test.

coefficients in the tropical Indian-western Pacific region $\left(40^{\circ}-\right.$ $180^{\circ} \mathrm{E}, 30^{\circ} \mathrm{S}-30^{\circ} \mathrm{N}$ ) of the OLR anomalies in Fig. $5 \mathrm{a}$ and the eight typical MJO phases are compared (not shown). The highest correlation coefficient across all MJO phases is found for phase 7 with a value of 0.59 . In addition, the enhanced convection anomalies in the WNP have maximum magnitude during phase 7 (Fig. 5c), highlighting the possible link between the enhanced WNP convective heating and the anticyclonic circulation anomalies over eastern Europe.

It is apparent that the meridional cold advection toward East Asia around phase 3 results from the 10-day lagged and accumulated response to the tropical convective forcing prior to phase 3 (Fig. 5). The enhanced convection anomalies in the WNP are particularly strong during phase 7 and presumably play a role in initiating the anomalous cold events in East Asia during phase 3. This tropics-extratropics teleconnection is present in the spatial and temporal evolution of the uppertropospheric height anomalies and found to be a result of Rossby wave energy propagation.

Overall, the convective forcing in the WNP as shown in Fig. 5 may be the possible source leading to the upper-level atmospheric circulation anomalies over eastern Europe. To highlight the meridionally propagating Rossby wave train from its initial source region in the WNP, the sequential evolution of upper-tropospheric wave activity flux and streamfunction anomalies are shown in Fig. 6 for the cases when the areaaveraged OLR anomalies located in the WNP are less than a negative one standard deviation threshold. Here, a negative OLR is indicative of enhanced convection in this region. On day 0 , strong enhanced convection anomalies are located in the western Pacific and coupled with suppressed convection anomalies in the tropical Indian Ocean, representative of the OLR pattern during phase 7 (Fig. 6a). The waves generally originate from the WNP region and then propagate northeastward across the northern Pacific toward North America.

The distinct anticyclonic anomalies are formed in eastern Europe from day 6 onward (Figs. 6c,d) and maintained until day 15 (not shown), supporting the anticyclone development as shown in Fig. 4. The wave activity from the enhanced WNP convection anomalies traverses the eastern Europe region and propagates farther downstream after about day 10. As discussed in Seo et al. (2016), according to a ray-tracing analysis the zonal wavenumber 4 emitted from the western Pacific can reach eastern Europe via the eastern Atlantic-Europe 

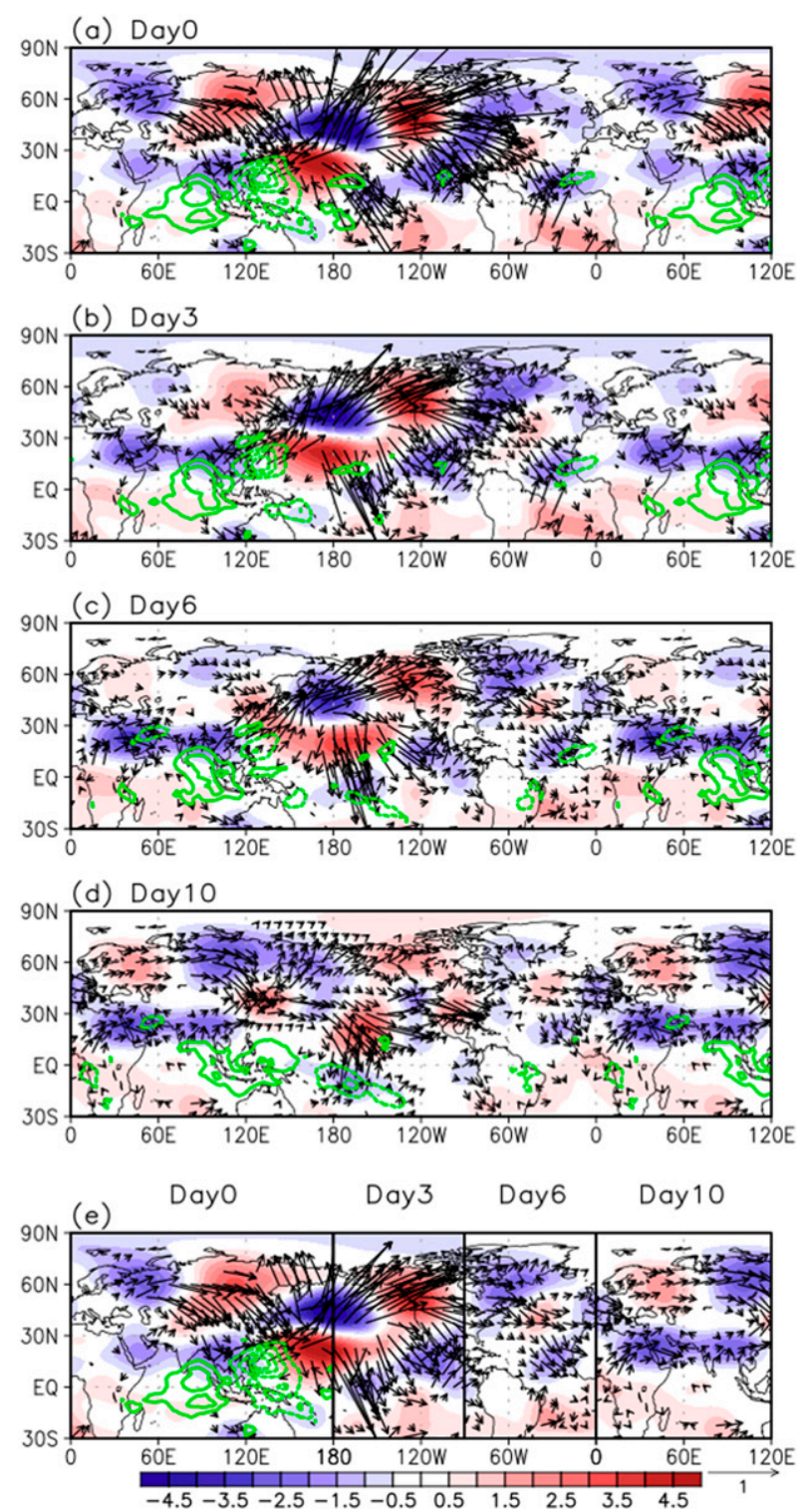

FIG. 6. Composites of OLR (contours; $\mathrm{W} \mathrm{m}^{-2}$ ), lagged composites of streamfunction (shading; $10^{6} \mathrm{~m}^{2} \mathrm{~s}^{-1}$ ), and horizontal evolutions of wave activity flux (vectors; $\mathrm{m}^{2} \mathrm{~s}^{-2}$ ) at $300 \mathrm{hPa}$ when the area-averaged $\mathrm{WNP}\left(120^{\circ}-140^{\circ} \mathrm{E}, 10^{\circ}-25^{\circ} \mathrm{N}\right)$ indices are less than -1 standard deviation at days (a) 0 , (b) 3 , (c) 6 , and (d) 10 . (e) The sequential evolution of upper-tropospheric wave activity flux and streamfunction anomalies from day 0 to day 10 are placed next to each other, joined by common longitude lines. Values exceeding 0.05 from day 0 to day 3 and 0.02 from day 6 to day 10 only are represented by wind vectors.

waveguide (Hoskins and Ambrizzi 1993). The wave activity propagation eventually reaches the East Asian region, before bending back toward the equator and affecting equatorial circulation initially induced by equatorially trapped Rossby and Kelvin waves (Seo et al. 2016).

This wave activity propagation path supports the hypothesis that the development of anticyclonic circulation anomalies in eastern Europe results from the Rossby wave dispersion of MJO-related diabatic heating anomalies in the WNP with a lag of about 10-15 days. Consequently, the anticyclonic anomalies over eastern Europe once developed induce the meridional cold advection toward East Asia, implying that through the Rossby wave propagation, the cold anomalies in East Asia are partly forced by the enhanced convection anomalies in the WNP.

\section{c. Vertical advection by $M J O$}

The temperature change accompanying the intraseasonal vertical advection is another important contributor to the cooling tendency in East Asia, as shown in Fig. 3. To understand the origin of the vertical advection in East Asia, an areaaveraged $\left(60^{\circ}-120^{\circ} \mathrm{E}, 25^{\circ}-55^{\circ} \mathrm{N}\right)$ vertical motion at $850 \mathrm{hPa}$ is defined as a vertical motion index. Figure 7 a shows the leading convection pattern in the Indian-western Pacific Ocean associated with the East Asian upward motion when the index exceeds a one standard deviation threshold. There are strong suppressed convection anomalies in the tropical Indian Ocean and relatively weak convection anomalies are confined in the off-equatorial western Pacific 10 days prior to the establishment of adiabatic cooling in East Asia. This leading OLR pattern of the ascending motion in East Asia is similar to that of the anticyclone anomalies development over eastern Europe (Fig. 5a), indicating that the MJO-related meridional and vertical advection in East Asia are largely forced by tropical convection perturbations during phase 7 . The pattern correlation coefficients of the tropical OLR field $\left(40^{\circ}-180^{\circ} \mathrm{E}\right.$, $30^{\circ} \mathrm{S}-30^{\circ} \mathrm{N}$ ) in Fig. $7 \mathrm{a}$ and the eight typical MJO phases support this link, whereby the highest correlation of 0.56 is during phase 7 .

The area-averaged suppressed convection in the tropical Indian Ocean $\left(60^{\circ}-100^{\circ} \mathrm{E}, 5^{\circ} \mathrm{S}-5^{\circ} \mathrm{N}\right)$ appears a maximum of 10 days ahead of the vertical motion in East Asia (Fig. 7b). In addition, the suppressed convection anomalies in the Indian Ocean are strongest during phase 7 (Fig. 7c). Therefore, the suppressed convection anomalies in the tropical Indian Ocean likely contribute to the upward motion and adiabatic cooling in East Asia about 10 days later. During phase 3 it has also been suggested that strong Indian Ocean convective heating is responsible for opposite impacts on the East Asian region, leading to the warming tendency after phase 3 (Seo et al. 2016) mainly due to adiabatic warm advection (Fig. 3). As a result, the overall warm anomalies are located in East Asia during phase 7 (Fig. 1g).

To display the dynamical process of suppressed Indian Ocean convection and lagged vertical cold advection in East Asia, the time evolution of MJO-related vertical motion is shown in Fig. 8. All variables are averaged from $60^{\circ}$ to $120^{\circ} \mathrm{E}$ after masking out the topographic effect of the Tibetan Plateau below $850 \mathrm{hPa}$. When the zonally averaged OLR anomalies in the tropical Indian Ocean are greater than a 1-standarddeviation threshold, representing anomalously suppressed convection, by day 5 significant upward motion exists along $45^{\circ} \mathrm{N}$ (Figs. 8a,b). This regional-scale meridional overturning circulation is defined as a local overturning circulation, which is simply reversed in direction here. The local overturning 

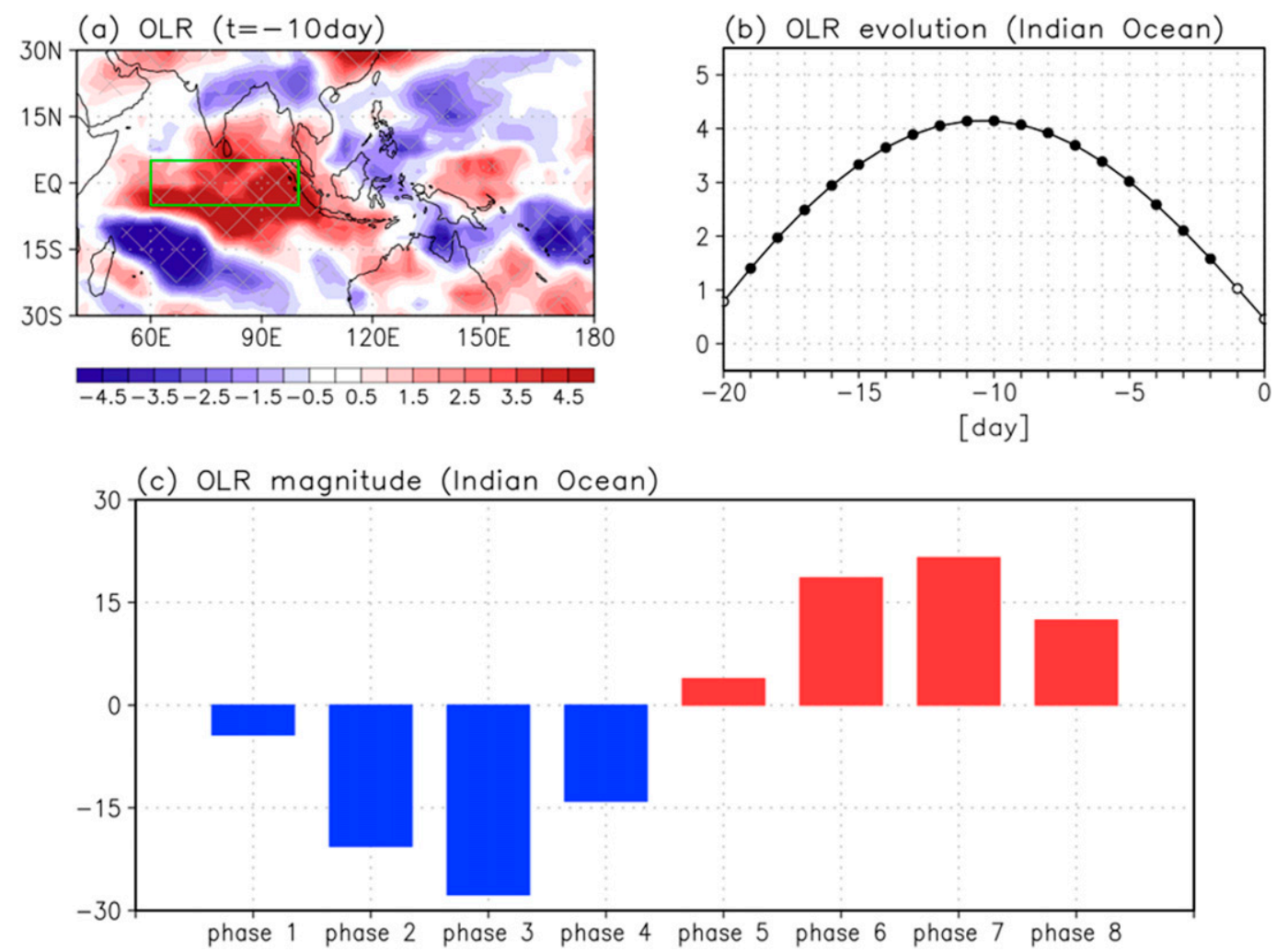

FIG. 7. (a) The leading OLR (shading; $\mathrm{W} \mathrm{m}^{-2}$ ) anomalies in the tropics 10 days before the area-averaged pressure velocity at $850 \mathrm{hPa}$ in East Asia (Fig. 2e; $60^{\circ}-120^{\circ} \mathrm{E}, 25^{\circ}-55^{\circ} \mathrm{N}$ ) are greater than 1 standard deviation. (b) The leading evolution of area-averaged OLR anomalies in the tropical Indian Ocean [green-framed rectangle in (a); $60^{\circ}-100^{\circ} \mathrm{E}, 5^{\circ} \mathrm{S}-5^{\circ} \mathrm{N}$ ] prior to the development of vertical motion in East Asia. (c) Composites of area-averaged OLR anomalies in the tropical Indian Ocean for the eight phases of the MJO. Cross hatches in (a), closed circles in (b), and bars in (c) denote statistically significant area at the $95 \%$ confidence level as based on Student's $t$ test.

circulation from the tropical Indian Ocean appears to be a key driver of upward motion in the midlatitudes and leads the adiabatic cooling by about 15-20 days (Figs. 8d,e). Therefore, the East Asian cooling is associated with the adiabatic upward motion in East Asia, of which is forced by the MJO-related suppressed convection in the tropical Indian Ocean. This supports the result of Seo et al. (2016) whereby the adiabatic subsidence in East Asia occurred following MJO phase 3.

\section{Summary and discussion}

In this study, the dynamical processes of how tropical MJO forcing leads to cold surface temperature anomalies in East Asia are investigated. It is evident that there is a time-lagged response on the East Asian temperature tendency about 10 days after tropical MJO forcing. The resultant cooling tendency in East Asia is found to initially appear prior to MJO phase 3, and then the cold anomalies are sustained across the East Asian region during phase 3; it also takes about 10 days to reach maximum cold anomalies. Thus, the MJO-related tropical forcing modulates the East Asian cold anomalies with a lag of approximately 20 days, almost half the period of the general MJO life cycle. Using the thermodynamic budget analysis, both meridional and vertical cold advections are found to be the dominant factors contributing to the cooling tendency in East Asia. The meridional cold advection exists in the form of northerly wind anomalies as the eastern part of anticyclonic flow is centered over eastern Europe. A precursory wave train for such a meridional cold advection in East Asia is excited by the WNP forcing consistent with forced Rossby wave theories. In addition, anomalous vertical motion in East Asia relies on direct tropical forcing originating from the tropical Indian Ocean and is interpreted as a local overturning circulation. The reversed local overturning circulation is intensified, leading to descending motion by the MJO convergent tropical inflow and enhanced momentum divergence around the extratropics together with adiabatic cold advection. Therefore, both the Rossby wave propagation and a local overturning circulation induced by the tropical MJO forcings play a direct role in influencing the temperature tendency in East Asia with a lag of about 10 days that leads surface temperature variation. The schematic diagram summarizes the two possible teleconnection pathways that explain the MJO journey by way of the Rossby wave train and local overturning circulation (Fig. 9).

The two distinguished dynamical processes, the meridional and vertical cold advections, appear to be forced by enhanced 

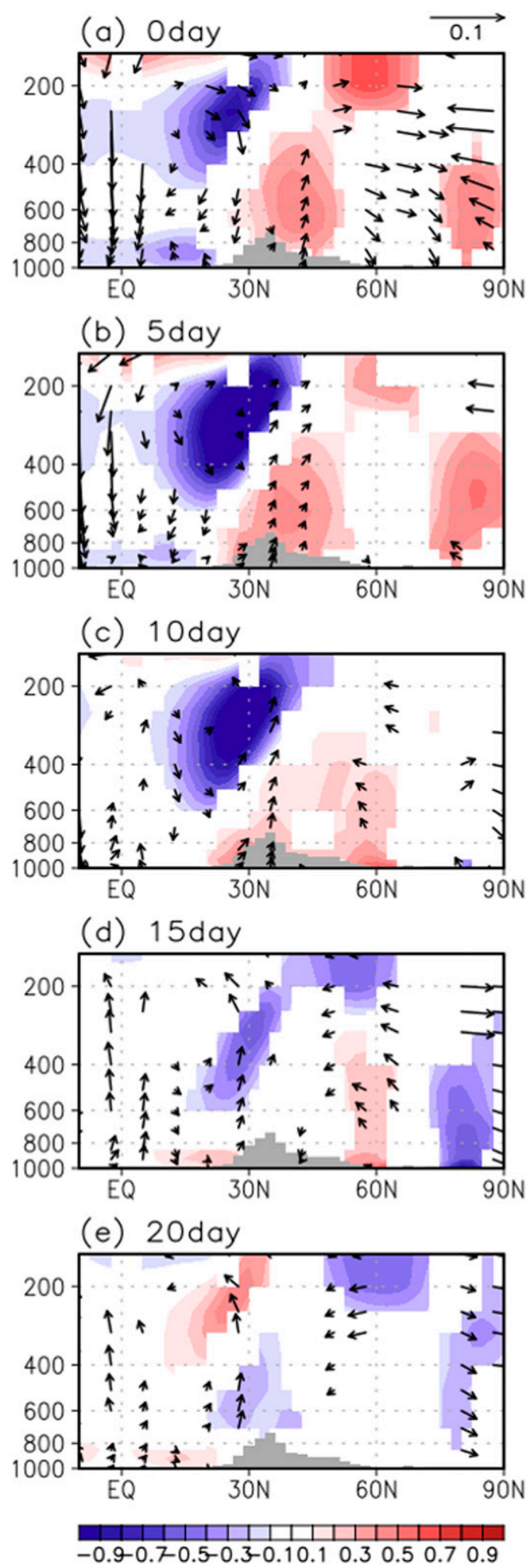

FIG. 8. Latitude-height cross section of lagged composites of air temperature (shading; K) and vertical flow (black arrows) at 5-day intervals when the area-averaged OLR anomalies in the tropical Indian Ocean are greater than 1 standard deviation, indicative of an anomalous suppressed convection. The magnitude of the diabatic heating in the WNP and suppressed convection in the tropical Indian Ocean, respectively. However, the tropical convective forcings that act as the source of the East Asian cooling closely resembles to a large extent the typical convection pattern during MJO phase 7. Therefore, it is possible that the east-west dipole convection in the tropical Indian Ocean and tropical western Pacific concurrently affects the East Asian surface temperature in terms of a teleconnection response. He et al. (2011) suggested that the linearized primitive equation model responses to such dipole heating sources closely match the general features of the observed circulation anomalies compared to those of simply single convection. This is also consistent with Lin et al. (2010b), who indicated that a dipole tropical convection initial state provides better skill than that when the initial MJO mostly has a monopole convection structure for NAO forecasts. Using linear numerical model experiments Lin et al. (2010a) also demonstrated that dipolelike tropical heating is more effective in extratropical atmospheric circulation perturbations associated with the North American precipitation than a single heating source near the western Pacific.

Overall, the dipole MJO diabatic heating source in the tropical Indian Ocean and western Pacific seems to strongly influence the large-scale extratropical circulation anomalies. To make a simple comparison of the individual responses from monopole and dipole thermal forcing described as phase 7 , composites for the three types of convective events are analyzed: Indian Ocean forcing only, west Pacific (WP) forcing only, and dipole forcing (Fig. 10). For the Indian Ocean and WP forcings only, the resulting cold anomalies as a lagged response are insufficient in developing broadly in East Asia. However, the dipole forcing with strong tropical Indian Ocean and WP convection shows strong cold anomalies in East Asia with a lag of about 20-25 days. The MJO-related dipole forcing plays an important role in determining the East Asian temperature variation during the boreal winter; therefore, such tropical precursors can help us to better understand and predict the wintertime weather in East Asia.

The present study focuses only on the causality of cold anomalies in East Asia associated with the MJO-driven tropical forcing during MJO phase 3. Interestingly, East Asia also experiences warmer than normal weather during phase 7 via similar MJO-induced teleconnections. Therefore, the warm and cold anomalies continuously fluctuate in East Asia, as shown in Fig. 1, because the MJO exhibits a repetitive cycle. However, here it is found that there is a distinct difference between warming and cooling tendencies in East Asia in terms of magnitude and main contributing terms (not shown). For

reference wind vector 0.1 denotes $25 \mathrm{~m} \mathrm{~s}^{-1}$ day $^{-1}$ for the meridional wind and $0.2 \mathrm{~Pa} \mathrm{~s}^{-1} \mathrm{day}^{-1}$ for the pressure velocity. All variables are zonally averaged from $60^{\circ}$ to $120^{\circ} \mathrm{E}$ after masking out the topographic effect of the Tibetan Plateau below $850 \mathrm{hPa}$. Shading and vectors represent statistically significant area at the $95 \%$ confidence level as based on Student's $t$ test. 


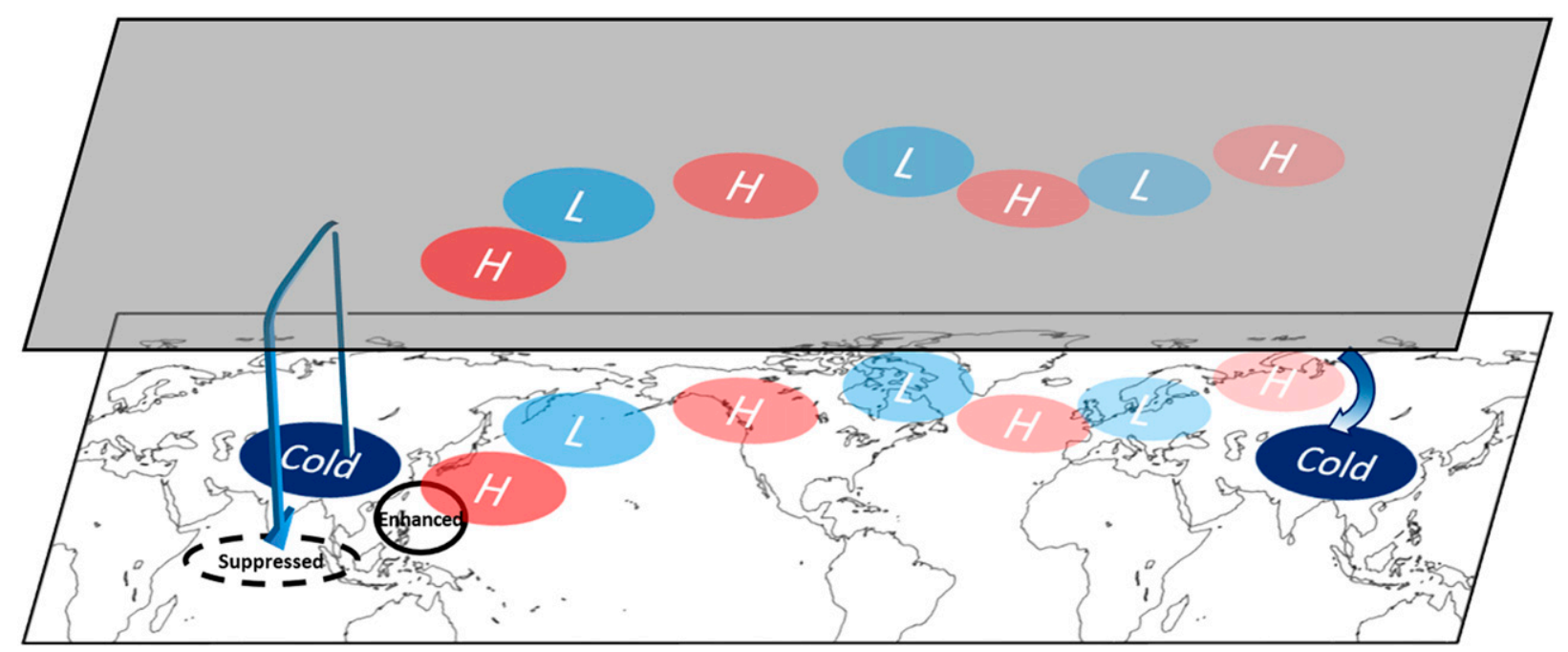

FIG. 9. Schematic diagram showing the local overturning circulation and Rossby wave propagation mechanisms of cold surface temperature anomalies in East Asia associated with delayed and accumulated response. The local overturning circulation is denoted as the reversed meridional overturning circulation with subsidence in the tropical Indian Ocean and an ascending branch induced by the adiabatic cold advection in East Asia. The Rossby wave propagation is identified as the upper-level geopotential height anomalies (cyclone or anticyclone) forced by enhanced convection in the WNP associated with the MJO. The meridional cold advection in East Asia is induced by northerly wind anomalies as part of the lower-tropospheric anticyclonic flow in the eastern Europe region.

example, the warming tendency associated with warm temperature anomalies during phase 7 is about 2 times as large as that during phase 3 , and the vertical warm advection predominantly contributes to the warming tendency. As a result of the strong warming tendency, the warm temperature anomalies may persist longer in East Asia after phase 7 relative to the cold-period events. Overall, the results show that the MJO could be utilized as a potential prediction source for the warm or cold anomalies in East Asia. Therefore, further examination of the features and predictabilities of the MJO-forced asymmetric impacts on the East Asian warm and cold anomalies in boreal winter is needed.

$$
\text { day } 0
$$
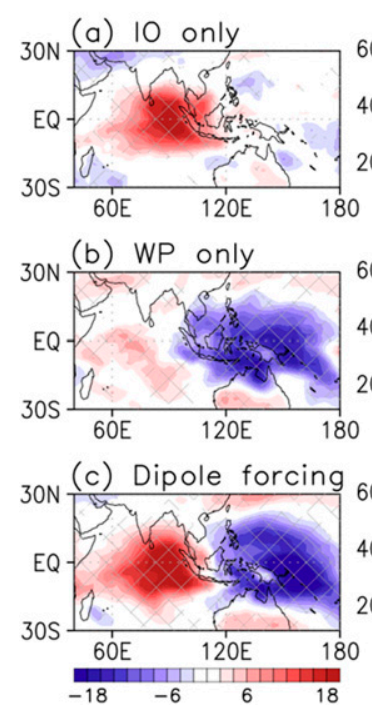
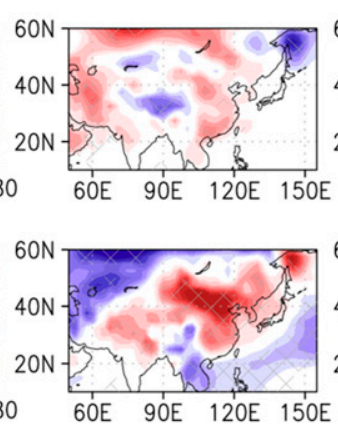

day 10

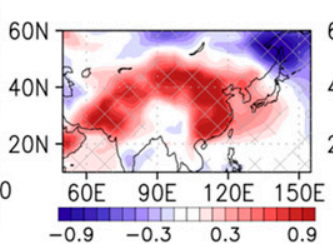

day 15
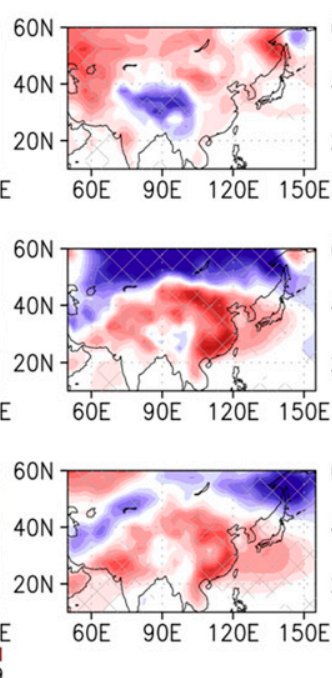

day 20
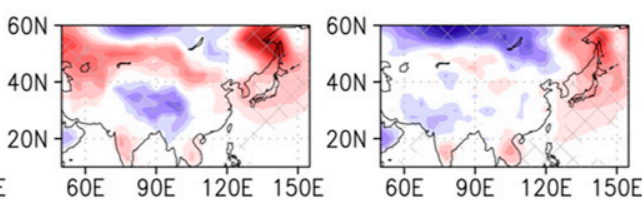

day 25

FIG. 10. Composites of OLR $\left(\mathrm{W} \mathrm{m}^{-2}\right)$ anomalies at day 0 in the tropics and lagged air temperature (K) anomalies at $2 \mathrm{~m}$ in East Asia from day 10 to day 25 , with an interval of 5 days, for an initial (a) Indian Ocean $\left(60^{\circ}-110^{\circ} \mathrm{E}, 15^{\circ} \mathrm{S}-15^{\circ} \mathrm{N}\right)$ only, (b) WP $\left(120^{\circ}-180^{\circ} \mathrm{E}, 15^{\circ} \mathrm{S}-\right.$ $15^{\circ} \mathrm{N}$ ) only, and (c) dipole forcing. For the Indian Ocean only, both Indian Ocean index exceeds its 0.5 standard deviation and the WP index lies between \pm 0.25 standard deviation. For the WP only, both the WP index exceeds its 0.5 standard deviation and the Indian Ocean index lies between \pm 0.25 standard deviation. The dipole forcing is defined when the difference of area-averaged OLR anomalies in the Indian Ocean and WP is greater than 1 standard deviation. Cross hatches denote statistically significant regions at the $95 \%$ confidence level as based on Student's $t$ test. The definition of "day $x$ " is the number of days after the individual forcing developed. 
Acknowledgments. We thank Prof. Daehyun Kim for insightful comments and discussions that greatly improved the paper. This study is supported by the Korea Meteorological Administration Research and Development Program under Grant KMIPA 2018-03212 and the National Research Foundation of Korea (NRF-2018RA5A1024958). Author Kyong-Hwan Seo is supported by the National Research Foundation of Korea (NRF-2020R1A2C2009414).

\section{REFERENCES}

Adames, Á. F., and J. M. Wallace, 2014: Three-dimensional structure and evolution of the MJO and its relation to the mean flow. J. Atmos. Sci., 71, 2007-2026, https://doi.org/ 10.1175/JAS-D-13-0254.1.

Adams, J. M., N. A. Bond, and J. E. Overland, 2000: Regional variability of the Arctic heat budget in fall and winter. J. Climate, 13, 3500-3510, https://doi.org/10.1175/1520-0442(2000)013<3500: RVOTAH $>2.0 . \mathrm{CO} ; 2$.

Barlow, M., M. Wheeler, B. Lyon, and H. Cullen, 2005: Modulation of daily precipitation over southwest Asia by the MaddenJulian oscillation. Mon. Wea. Rev., 133, 3579-3594, https:// doi.org/10.1175/MWR3026.1.

Bond, N. A., and G. A. Vecchi, 2003: The influence of the MaddenJulian oscillation on precipitation in Oregon and Washington. Wea. Forecasting, 18, 600-613, https://doi.org/10.1175/15200434(2003)018<0600:TIOTMO > 2.0.CO;2.

Cassou, C., 2008: Intraseasonal interaction between the MaddenJulian oscillation and the North Atlantic Oscillation. Nature, 455, 523-527, https://doi.org/10.1038/nature07286.

He, J., H. Lin, and Z. Wu, 2011: Another look at influences of the Madden-Julian oscillation on the wintertime East Asian weather. J. Geophys. Res., 116, D03109, https://doi.org/10.1029/ 2010JD014787.

Hoskins, B. J., and T. Ambrizzi, 1993: Rossby wave propagation on a realistic longitudinally varying flow. J. Atmos. Sci., 50, 1661-1671, https://doi.org/10.1175/1520-0469(1993)050<1661: RWPOAR $>2.0 . \mathrm{CO} ; 2$.

Hsu, H.-H., 1996: Global view of the intraseasonal oscillation during northern winter. J. Climate, 9, 2386-2406, https://doi.org/10.1175/ 1520-0442(1996)009<2386:GVOTIO > 2.0.CO;2.

Hurrell, J. W., 1995: Decadal trends in the North Atlantic Oscillation: Regional temperatures and precipitation. Science, 269, 676-679, https://doi.org/10.1126/science.269.5224.676.

Jeong, J.-H., C.-H. Ho, B.-M. Kim, and W.-T. Kwon, 2005: Influence of the Madden-Julian Oscillation on wintertime surface air temperature and cold surges in East Asia. J. Geophys. Res., 110, D11104, https://doi.org/10.1029/2004JD005408.

— B. Kim, C. Ho, and Y. Noh, 2008: Systematic variation in wintertime precipitation in East Asia by MJO-induced extratropical vertical motion. J. Climate, 21, 788-801, https:// doi.org/10.1175/2007JCLI1801.1.

Jin, F., and B. J. Hoskins, 1995: The direct response to tropical heating in a baroclinic atmosphere. J. Atmos. Sci., 52, 307-319, https:// doi.org/10.1175/1520-0469(1995)052<0307:TDRTTH>2.0.CO;2.

Jones, C., 2000: Occurrence of extreme precipitation events in California and relationships with the Madden-Julian oscillation. J. Climate, 13, 3576-3587, https://doi.org/10.1175/15200442(2000)013<3576:OOEPEI > 2.0.CO;2.

— D. E. Waliser, K. M. Lau, and W. Stern, 2004: The MaddenJulian oscillation and its impact on Northern Hemisphere weather predictability. Mon. Wea. Rev., 132, 1462-1471, https:// doi.org/10.1175/1520-0493(2004)132<1462:TMOAII>2.0.CO;2.
Kalnay, E., and Coauthors, 1996: The NCEP/NCAR 40-Year Reanalysis Project. Bull. Amer. Meteor. Soc., 77, 437-471, https:/doi.org/ 10.1175/1520-0477(1996)077<0437:TNYRP>2.0.CO;2.

Knutson, T. R., and K. M. Weickmann, 1987: 30-60 day atmospheric oscillations: Composite life cycles of convection and circulation anomalies. Mon. Wea. Rev., 115, 1407-1436, https://doi.org/ 10.1175/1520-0493(1987)115<1407:DAOCLC > 2.0.CO;2.

Liebmann, B., and C. A. Smith, 1996: Description of a complete (interpolated) outgoing longwave radiation dataset. Bull. Amer. Meteor. Soc., 77, 1275-1277, https://doi.org/10.1175/ 1520-0477-77.6.1274.

Lin, H., G. Brunet, and J. Derome, 2009: An observed connection between the North Atlantic Oscillation and the MaddenJulian oscillation. J. Climate, 22, 364-380, https://doi.org/ 10.1175/2008JCLI2515.1.

$\longrightarrow, \ldots$, and R. Mo, 2010a: Impact of the Madden-Julian oscillation on wintertime precipitation in Canada. Mon. Wea. Rev., 138, 3822-3839, https://doi.org/10.1175/2010MWR3363.1.

,-- , and J. S. Fontecilla, 2010b: Impact of the MaddenJulian Oscillation on the intraseasonal forecast skill of the North Atlantic Oscillation. Geophys. Res. Lett., 37, L19803, https://doi.org/10.1029/2010GL044315.

Madden, R. A., and P. R. Julian, 1971: Detection of a 40-50 day oscillation in the zonal wind in the tropical Pacific. J. Atmos. Sci., 28, 702-708, https://doi.org/10.1175/1520-0469(1971) 028<0702:DOADOI $>2.0 . \mathrm{CO} ; 2$.

$\longrightarrow$, and -1972 : Description of global-scale circulation cells in the tropics with a 40-50 day period. J. Atmos. Sci., 29, 11091123, https://doi.org/10.1175/1520-0469(1972)029<1109: DOGSCC $>2.0 . \mathrm{CO} ; 2$

Majda, A. J., and S. N. Stechmann, 2009: The skeleton of tropical intraseasonal oscillations. Proc. Natl. Acad. Sci. USA, 106, 8417-8422, https://doi.org/10.1073/pnas.0903367106.

Matthews, A. J., 2000: Propagation mechanisms for the MaddenJulian oscillation. Quart. J. Roy. Meteor. Soc., 126, 2637-2651, https://doi.org/10.1002/qj.49712656902.

_ B. B. Hoskins, and M. Masutani, 2004: The global response to tropical heating in the Madden-Julian oscillation during the northern winter. Quart. J. Roy. Meteor. Soc., 130, 1991-2011, https://doi.org/10.1256/qj.02.123.

Mo, K. C., and R. Higgins, 1998: Tropical convection and precipitation regimes in the western United States. J. Climate, 11, 2404-2423, https:// doi.org/10.1175/1520-0442(1998)011<2404:TCAPRI>2.0.CO;2.

Paegle, J. N., L. A. Byerle, and K. C. Mo, 2000: Intraseasonal modulation of South American summer precipitation. Mon. Wea. Rev., 128, 837-850, https://doi.org/10.1175/1520-0493(2000)128<0837: IMOSAS>2.0.CO;2.

Qiu, J., 2008: China: The third pole. Nature, 454, 393-396, https:// doi.org/10.1038/454393a.

Rui, H., and B. Wang, 1990: Development characteristics and dynamic structure of tropical intraseasonal convection anomalies. J. Atmos. Sci., 47, 357-379, https://doi.org/10.1175/15200469(1990)047<0357:DCADSO > 2.0.CO;2.

Seo, K.-H., and S.-W. Son, 2012: The global atmospheric circulation response to tropical diabatic heating associated with the Madden-Julian oscillation during northern winter. J. Atmos. Sci., 69, 79-96, https://doi.org/10.1175/2011JAS3686.1.

_ , and H.-J. Lee, 2017: Mechanisms for a PNA-like teleconnection pattern in response to the MJO. J. Atmos. Sci., 74, 1767-1781, https://doi.org/10.1175/JAS-D-16-0343.1.

- — , and D. M. W. Frierson, 2016: Unraveling the teleconnection mechanisms that induce wintertime temperature anomalies over the Northern Hemisphere continents in response 
to the MJO. J. Atmos. Sci., 73, 3557-3571, https://doi.org/ 10.1175/JAS-D-16-0036.1.

Sobel, A., and E. Maloney, 2013: Moisture modes and the eastward propagation of the MJO. J. Atmos. Sci., 70, 187-192, https:// doi.org/10.1175/JAS-D-12-0189.1.

Stan, C., D. M. Straus, J. S. Frederiksen, H. Lin, E. D. Maloney, and C. Schumacher, 2017: Review of tropical-extratropical teleconnections on intraseasonal time scales. Rev. Geophys., 55 , 902-937, https://doi.org/10.1002/2016RG000538.

Takaya, K., and H. Nakamura, 2001: A formulation of a phaseindependent wave-activity flux for stationary and migratory quasigeostrophic eddies on a zonally varying basic flow. J. Atmos. Sci., 58, 608-627, https://doi.org/10.1175/1520-0469 (2001) $058<0608$ :AFOAPI $>2.0$. CO;2.

Vecchi, G. A., and N. A. Bond, 2004: The Madden-Julian Oscillation (MJO) and northern high latitude wintertime surface air temperatures. Geophys. Res. Lett., 31, L04104, https://doi.org/10.1029/2003GL018645.

Wang, B., and H. Rui, 1990: Dynamics of the coupled moist Kelvin-Rossby wave on an equatorial $\beta$-plane. J. Atmos. Sci., 47, 397-413, https:// doi.org/10.1175/1520-0469(1990)047<0397:DOTCMK >2.0.CO;2.

_, F. Liu, and G. Chen, 2016: A trio-interaction theory for Madden-Julian oscillation. Geosci. Lett., 3, 34, https://doi.org/ 10.1186/s40562-016-0066-z.

Wang, L., and T. Li, 2020: Effect of vertical moist static energy advection on MJO eastward propagation: Sensitivity to analysis domain. Climate Dyn., 54, 2029-2039, https://doi.org/ 10.1007/s00382-019-05101-8.

- — - T. Zhou, and X. Rong, 2013: Origin of the intraseasonal variability over the North Pacific in boreal summer. J. Climate, 26, 1211-1229, https://doi.org/10.1175/JCLI-D-11-00704.1.
,-- , E. Maloney, and B. Wang, 2017: Fundamental causes of propagating and nonpropagating MJOs in MJOTF/GASS models. J. Climate, 30, 3743-3769, https://doi.org/10.1175/ JCLI-D-16-0765.1.

Wheeler, M. C., and H. H. Hendon, 2004: An all-season real-time multivariate MJO index: Development of an index for monitoring and prediction. Mon. Wea. Rev., 132, 1917-1932, https://oi.org/ 10.1175/1520-0493(2004)132<1917:AARMMI>2.0.CO;2.

Yanai, M., S. Esbensen, and J. Chu, 1973: Determination of bulk properties of tropical cloud clusters from large-scale heat and moisture budgets. J. Atmos. Sci., 30, 611-627, https://doi.org/ 10.1175/1520-0469(1973)030<0611:DOBPOT>2.0.CO;2.

Yang, D., and A. P. Ingersoll, 2013: Triggered convection, gravity waves, and the MJO: A shallow-water model. J. Atmos. Sci., 70, 2476-2486, https://doi.org/10.1175/JAS-D-12-0255.1.

Yang, S., and T. Li, 2016: Intraseasonal variability of air temperature over the mid-high latitude Eurasia in boreal winter. Climate Dyn., 47, 2155-2175, https://doi.org/10.1007/s00382015-2956-8.

- , and,- 2017 : Causes of intraseasonal diabatic heating variability over and near the Tibetan Plateau in boreal summer. Climate Dyn., 49, 2385-2406, https://doi.org/10.1007/ s00382-016-3463-2.

Yoo, C., S. Lee, and S. B. Feldstein, 2012: Mechanisms of Arctic surface air temperature change in response to the MaddenJulian oscillation. J. Climate, 25, 5777-5790, https://doi.org/ 10.1175/JCLI-D-11-00566.1.

Zhao, C., T. Li, S. Yao, S. K. Behera, and T. Nasuno, 2017: Intraseasonal variability of air temperature over East Asia in boreal summer. Front. Earth Sci., 5, 63, https://doi.org/10.3389/ feart.2017.00063. 